\title{
Amlodipine Reduces Inflammation despite Promoting Albuminuria in the Streptozotocin-Induced Diabetic Rat
}

\author{
Elizabeth R. Flynn ${ }^{a} \quad$ David C. Marbury ${ }^{a} \quad$ R. Taylor Sawyer ${ }^{a}$ \\ Jonathan Lee ${ }^{a}$ Christine Teutsch $^{d}$ Katalin Kauser ${ }^{c}$ \\ Christine Maric-Bilkan ${ }^{a, b}$ \\ ${ }^{a}$ Department of Physiology and Biophysics, University of Mississippi Medical Center, and \\ ${ }^{b}$ Center for Excellence in Cardiovascular-Renal Research, Jackson, Miss., and \\ ${ }^{\mathrm{C} B o e h r i n g e r ~ I n g e l h e i m, ~ R i d g e f i e l d, ~ C o n n ., ~ U S A ; ~}{ }^{\mathrm{d} B o e h r i n g e r ~ I n g e l h e i m, ~ P h a r m a ~ G m b H ~ \& ~ C o ~}$ \\ KG, Ingelheim, Germany
}

\section{Key Words}

Diabetes $\cdot$ Dihydropyridine-type calcium channels $\cdot$ Kidney $\cdot$ Inflammation

\begin{abstract}
Amlodipine reduces blood pressure; however, its effect in the diabetic kidney irrespective of its blood pressure-lowering effects is unclear. This study examined the effects of amlodipine $(0,5$, 10 and $20 \mathrm{mg} / \mathrm{kg} ; D_{A 0}, D_{A 5}, D_{A 10}$ and $D_{A 20}$, respectively) for 12 weeks on renal functional and structural changes in the streptozotocin-induced diabetic rat, a nonhypertensive model of diabetes-associated hyperfiltration. Compared with nondiabetic rats, diabetes (D) was associated with increased urine albumin excretion (UAE, $12.6 \pm 3.40$ vs. $3.73 \pm 1.14 \mathrm{mg} /$ day), glomerular filtration rate $(2.17 \pm 0.09$ vs. $1.64 \pm 0.12 \mathrm{ml} / \mathrm{min} / \mathrm{g}$ kidney weight), glomerulosclerosis $(0.21 \pm$ 0.03 vs. $0.05 \pm 0.01 \mathrm{AU}$ ) and infiltration of inflammatory cells (18.5 \pm 2.78 vs. $6.92 \pm 0.70$ cells/ $\mathrm{cm}^{2}$ ), but did not affect mean arterial pressure (MAP, $110 \pm 4.70 \mathrm{vs.} 109 \pm 5.33 \mathrm{~mm} \mathrm{Hg}$ ). While $\mathrm{D}_{\mathrm{A} 20}$ abolished glomerular hyperfiltration (1.49 $\pm 0.05 \mathrm{ml} / \mathrm{min} / \mathrm{g}$ kidney weight) and inflammatory cell abundance $\left(6.0 \pm 0.79\right.$ cells $\left./ \mathrm{cm}^{2}\right)$, it exacerbated UAE $(43.5 \pm 8.49 \mathrm{mg} / \mathrm{day})$ and increased MAP (132 $\pm 3.76 \mathrm{~mm} \mathrm{Hg}$ ), but had no effect on renal pathology. These data suggest that amlodipine reduces renal inflammation and abolished glomerular hyperfiltration, but increases blood pressure and exacerbates albuminuria in the rat model of normotensive diabetic kidney disease. We conclude that amlodipine may have limited renoprotective effects in the face of hyperfiltration and absence of elevated blood pressure.

Copyright $\odot 2012$ S. Karger AG, Basel
\end{abstract}




\section{Introduction}

In humans, dihydropyridine calcium channel blockers (CCBs), including amlodipine have been used, and lately more frequently, as blood pressure-lowering agents alone [1], or in combination with blockers of the renin-angiotensin system (RAS) [2]. In patients with chronic renal disease, amlodipine has been shown to have some additional renoprotective effects, at least in some studies. In hypertensive diabetic patients without overt renal disease, amlodipine has been shown to reduce microalbuminuria, albeit not to the same degree as angiotensin II type 1 receptor $\left(\mathrm{AT}_{1}\right)$ antagonists telmisartan [3], losartan [4], valsartan [5], irbesartan [6] or angiotensin converting enzyme (ACE) inhibitors such as benazapril [7] or lisinopril [8]. Studies, including the Avoiding Cardiovascular Events through Combination Therapy in Patients Living with Systolic Hypertension (ACCOMPLISH) trial demonstrated further blood pressure-lowering and renoprotective effects of the combination therapy of amlodipine and benazapril over either drug alone [7]. However, these beneficial effects of amlodipine on albuminuria are not universal, as studies in patients with chronic kidney disease and hypertension reported no effect [9-11] or even an increase [12] in albuminuria following treatment with amlodipine. Experimental models of chronic kidney disease have suggested that CCBs may impair autoregulation despite their blood pressure-lowering effects $[13,14]$. Furthermore, class differences in the effects of CCBs may also explain their equivocal effects in both experimental models and humans with chronic kidney disease [13].

Diabetes is the leading cause of end-stage renal disease and is associated with high mortality rates [15]. Similar to the effects of CCBs in nondiabetic renal disease, both beneficial and adverse effects of CCBs have been reported in patients with diabetic nephropathy. Specifically, in patients with diabetic nephropathy associated with type 1 diabetes, nisoldipine (long-acting dihydropyridine CCB) attenuates the rate of decline in glomerular filtration [16]. In patients with diabetic nephropathy associated with type 2 diabetes, amlodipine exacerbates albuminuria and decreases the estimated glomerular filtration rate (GFR) [17]. Similarly, the data in experimental models of diabetic renal disease are inconsistent, showing beneficial effects of a calcium antagonist TA-3090 (diltiazem-like) on albuminuria and glomerular hypertrophy $[18,19]$, but adverse effects on GFR [18]. As in nondiabetic chronic kidney disease, different classes of CCBs appear to exert differential effects in the diabetic kidney as well. While several studies have implied that CCBs may have a direct renoprotective effect irrespective of their blood pressure-lowering ability, this has not directly been tested in an experimental model of diabetic renal disease. Thus, the aim of the present study was to examine some of the mechanisms of action of a dihydropyridine CCB, amlodipine, in the streptozotocin (STZ)-induced diabetic rat, a model of diabetic renal disease not associated with hypertension.

\section{Methods and Materials}

\section{Study Design}

The study was performed in 12-week-old male Sprague-Dawley rats (Harlan, Madison, Wisc., USA) fed a standard rat diet and allowed free access to tap water. The animals were randomly divided to remain either nondiabetic $(n=8)$ or rendered diabetic with a single i.p. injection of STZ (55 mg/kg in $0.1 \mathrm{~mm}$ citrate buffer, $\mathrm{pH}$ 7.4) as previously described [20]. At the time of initiation of diabetes, the diabetic rats were further randomized to receive either vehicle $\left(D_{A 0}, n=10\right)$ or varying doses of amlodipine: $5 \mathrm{mg} / \mathrm{kg}\left(D_{\mathrm{A} 5}, \mathrm{n}=10\right), 10 \mathrm{mg} / \mathrm{kg}\left(\mathrm{D}_{\mathrm{A} 10}\right.$, $\mathrm{n}=8)$ and $20 \mathrm{mg} / \mathrm{kg}\left(\mathrm{D}_{\mathrm{A} 20}, \mathrm{n}=7\right)$. Amlodipine was dissolved in water and administered by oral gavage for 12 weeks. 
During the 12-week treatment period, all diabetic rats received insulin, s.c. every 3 days (2-4 U; Lantus, Aventis Pharmaceuticals Inc., Kansas City, Mo., USA) to maintain blood glucose levels between $300-450 \mathrm{mg} / \mathrm{dl}$ (measured using the OneTouch Ultra glucometer), promote weight gain and prevent mortality. The animals were placed in metabolic cages once every 4 weeks for $24 \mathrm{~h}$ and their urine was collected for measurement of urine output and albumin concentration. One day prior to sacrifice, the animals were instrumented with catheters for measurement of blood pressure and renal function as described below. Following an overnight recovery, these measurements were taken and the kidneys were removed and weighed. Parts of the kidney were snap frozen in liquid nitrogen (for protein analysis) while other parts were fixed with $10 \%$ buffered formalin (for histology and immunohistochemistry). At the time of sacrifice, $\mathrm{HbAl}_{\mathrm{C}}$ was measured in a sample of blood obtained from a tail prick using the A1CNow $+{ }^{\circledR}$ monitor (Bayer, Sunnyvale, Calif., USA) according to the manufacturer's protocol. All experiments were performed according to the guidelines recommended by the National Institutes of Health and approved by the University of Mississippi Medical Center Animal Care and Use Committee.

\section{Measurement of Mean Arterial Pressure and Renal Function}

Animals were anesthetized with $3 \%$ isoflurane and placed on a heating pad to maintain body temperature. Catheters were placed in the femoral artery for recording of arterial pressure and in the femoral vein for i.v. infusions and blood collection. The cannulae were routed under the skin to the nape of the neck. After overnight recovery, mean arterial pressure was continuously recorded for $2 \mathrm{~h}$ in conscious rats via a pressure transducer connected to a computerized data acquisition system (PowerLab, ADInstruments, Colorado Springs, Colo., USA). GFR was measured by infusing ${ }^{125} \mathrm{I}$-iothalamate $(10 \mu \mathrm{Ci} / \mathrm{ml})$ at a rate of $2 \mathrm{ml} / \mathrm{h}$ over $3 \mathrm{~h}$.

\section{Renal Renin Activity}

Renal cortical homogenates were prepared for analysis as previously described [21]. Renal renin activity was measured by radioimmunoassay using a modification of Haber and associates [22] with AI standards, tracer, and antibody from the National Bureau of Standards, New England Nuclear, and Arnel, respectively.

\section{Urine Albumin}

Urine albumin concentration was measured using the Nephrat II albumin kit (Exocell, Inc., Philadelphia, Pa., USA), according to the manufacturer's protocol.

\section{Renal Pathology}

Glomerulosclerosis was defined as mesangial expansion and glomerulosclerosis index (GSI) assessed using a standard, semiquantitative scoring method as previously described [20]. Briefly: grade 0 , no obvious sclerosis (normal); grade 1 , sclerotic area $<25 \%$ (minimal sclerosis); grade 2 , sclerotic area $25 \%$ to $50 \%$ (moderate sclerosis); grade 3 , sclerotic area $50 \%$ to $75 \%$ (moderate-severe sclerosis); grade 4 , sclerotic area $75 \%$ to $100 \%$ (severe sclerosis).

Tubulointerstitial fibrosis was defined as tubular atrophy or dilatation, deposition of ECM and presence of inflammatory cells and tubulointerstitial fibrosis index (TIFI) assessed using a standard, semiquantitative scoring method as previously described [20]. Briefly: grade 0 , no obvious damage; grade 1 , affected area $<10 \%$; grade 2 , affected area $10 \%$ to $25 \%$; grade 3 , affected area $25 \%$ to $75 \%$; grade 4 , affected area $75 \%$ to $100 \%$. Assessments of both GSI and TIFI were performed with the observer blinded to the treatment groups. 
Streptozotocin-Induced Diabetic Rat

Table 1. Metabolic and renal parameters

\begin{tabular}{lccccc}
\hline Parameters & $\mathrm{ND}(\mathrm{n}=8)$ & $\mathrm{D}_{\mathrm{A} 0}(\mathrm{n}=10)$ & $\mathrm{D}_{\mathrm{A} 5}(\mathrm{n}=10)$ & $\mathrm{D}_{\mathrm{A} 10}(\mathrm{n}=8)$ & $\mathrm{D}_{\mathrm{A} 20}(\mathrm{n}=7)$ \\
\hline HbA1 $\mathrm{C}, \%$ & $4.39 \pm 0.10$ & $10.1 \pm 0.45^{* * *}$ & $9.06 \pm 0.63^{* * *}$ & $9.33 \pm 0.33^{* * *}$ & $9.27 \pm 0.44^{* * *}$ \\
Body weight, g & $419 \pm 9.62$ & $300 \pm 7.0^{* * *}$ & $310 \pm 12.9^{* * *}$ & $306 \pm 6.88^{* * *}$ & $309 \pm 4.78^{* * *}$ \\
Kidney weight, g & $1.14 \pm 0.03$ & $1.46 \pm 0.03^{* * *}$ & $1.50 \pm 0.06^{* * *}$ & $1.44 \pm 0.04^{* * *}$ & $1.46 \pm 0.04^{* * *}$ \\
Kidney/body weight, g/kg & $2.80 \pm 0.07$ & $4.87 \pm 0.13^{* * *}$ & $4.91 \pm 0.16^{* * *}$ & $4.71 \pm 0.09^{* * *}$ & $4.73 \pm 0.15^{* * *}$ \\
Heart weight, g & $1.35 \pm 0.07$ & $1.21 \pm 0.04$ & $1.24 \pm 0.04$ & $1.26 \pm 0.05$ & $1.24 \pm 0.06$ \\
Heart/body weight, g/kg & $3.30 \pm 0.02$ & $4.05 \pm 0.15^{*}$ & $4.06 \pm 0.19^{*}$ & $4.11 \pm 0.12^{*}$ & $4.01 \pm 0.22^{*}$ \\
Food intake, g/day & $25.4 \pm 1.59$ & $45.2 \pm 2.31^{* *}$ & $44.7 \pm 2.17^{* *}$ & $47.3 \pm 2.81^{* * *}$ & $42.3 \pm 3.56^{* * *}$ \\
Water intake, ml/day & $30.1 \pm 2.66$ & $150 \pm 9.15^{* * *}$ & $146 \pm 6.17^{* * *}$ & $135 \pm 17.9^{* * *}$ & $195 \pm 11.5^{* * *, \dagger, \#, \$}$ \\
Urine output, ml/day & $16.1 \pm 2.19$ & $117 \pm 7.95^{* * *}$ & $116 \pm 4.90^{* * *}$ & $104 \pm 14.6^{* * *}$ & $162 \pm 4.08^{* * *, \dagger}, \#, \$ \$ \$$ \\
MAP, mm Hg & $110 \pm 4.70$ & $109 \pm 5.33$ & $118 \pm 2.46$ & $116 \pm 5.09$ & $132 \pm 3.76^{*}$, \\
Renal renin activity, ng Ang I/mg/h & $3.0 \pm 0.69$ & $5.60 \pm 0.32^{*}$ & $6.40 \pm 1.00^{*}$ & $6.48 \pm 0.67^{*}$ & $8.42 \pm 0.72^{* *}$ \\
\hline
\end{tabular}

Values are expressed as mean \pm SE. Statistical significance was accepted at $p<0.05 .{ }^{*} p<0.05$ versus ND; ${ }^{* *} p<0.01$ versus ND; ${ }^{* * *} \mathrm{p}<0.001$ versus ND; ${ }^{\dagger} \mathrm{p}<0.05$ versus $\mathrm{D}_{\mathrm{A} 0} ;{ }^{\dagger \dagger} \mathrm{p}<0.01$ versus $\mathrm{D}_{\mathrm{A} 0} ;{ }^{*} \mathrm{p}<0.05$ versus $\mathrm{D}_{\mathrm{A} 5} ;{ }^{\# \#} \mathrm{p}<0.01$ versus $\mathrm{D}_{\mathrm{A} 5}$; $\$ \mathrm{p}<0.05$ versus $\mathrm{D}_{\mathrm{A} 10} ; \$ \$ \$ \mathrm{p}<0.001$ versus DA10.

\section{Immunohistochemistry}

Paraffin-embedded sections $(4 \mu \mathrm{m})$ were incubated with $10 \%$ nonimmune goat serum for blocking of nonspecific immunolabeling. Following incubation at $4{ }^{\circ} \mathrm{C}$ overnight with the primary antisera against collagen type IV (1:400, affinity-purified goat anti-human, Southern Biotech, Birmingham, Ala., USA), TGF- $\beta$ (1:200, rabbit polyclonal, Cruz Biotech., Santa Cruz, Calif., USA) and CD68 (1:200, mouse monoclonal, Serotec, Raleigh, N.C., USA). Sections were then incubated with appropriate secondary, biotinylated IgGs and then with the avidin-biotin complex (Vectastain ABC kit, Elite, Vector Laboratories, Calif., USA). A positive immunoreaction was identified after a 10-min treatment with 3,3-diaminobenzidine and counterstaining with Mayer's hematoxylin. Sections incubated with $10 \%$ NGS instead of the primary antiserum were used as negative controls.

The density of CD68-positive cells was assessed in thirty randomly selected glomeruli and/or cortical interstitial regions per section and quantitated using image analysis software (NIS-Elements, Ver. 2.32; Nikon Instruments, Melville, N.Y., USA). The data are expressed as CD68-positive cells $/ \mathrm{mm}^{2}$ per selected area (glomerulus or cortical tubulointerstitial regions).

\section{Western Blotting}

Homogenized protein samples were denatured at $95^{\circ} \mathrm{C}$ for $10 \mathrm{~min}$, loaded onto SDSPAGE precast gels (Bio-Rad, Hercules, Calif., USA) and transferred to a nitrocellulose membrane. The membranes were incubated first with $5 \%$ non-fat milk and then with antisera against collagen type IV (1:500, affinity-purified goat anti-human, Southern Biotech, Birmingham, Ala., USA) and TGF- $\beta$ (1:500, rabbit polyclonal, Cruz Biotech., Santa Cruz, Calif., USA). The membranes were then incubated with appropriate secondary antibodies conjugated to horseradish peroxidase and proteins visualized by enhanced chemiluminescence (KPL, Gaithersburg, Md., USA). All membranes were then stripped and re-probed with an antibody against $\beta$-actin (1:3,000; mouse monoclonal, Cell Signaling, Danvers, Mass., USA). The densities of specific bands were quantitated by densitometry using the Scion Image beta (version 4.02) software and normalized to the total amount of protein loaded in each well following densitometric analysis of gels stained for $\beta$-actin. 

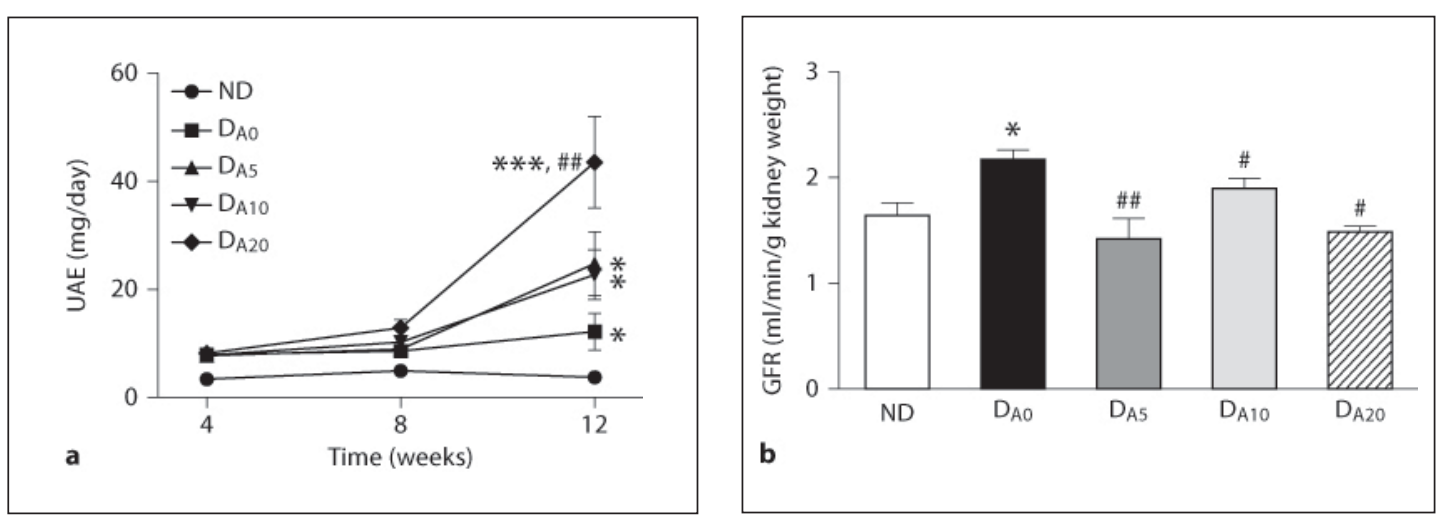

Fig. 1. Effects of amlodipine on renal function in the STZ-induced diabetic rat. a Urine albumin excretion (UAE). $\mathbf{b}$ Glomerular filtration rate (GFR). Values are means \pm SE. Nondiabetic (ND), $n=8 ; D_{A 0}, n=10$; $\mathrm{D}_{\mathrm{A} 5}, \mathrm{n}=10 ; \mathrm{D}_{\mathrm{A} 10}, \mathrm{n}=8 ; \mathrm{D}_{\mathrm{A} 20}, \mathrm{n}=7 .{ }^{*} \mathrm{p}<0.05$ versus $\mathrm{ND} ;{ }^{* *} \mathrm{p}<0.001$ versus $\mathrm{ND} ;{ }^{*} \mathrm{p}<0.05$ versus $\mathrm{D}_{\mathrm{A} 0}$; ${ }^{\# \#} \mathrm{p}<0.01$ versus $\mathrm{D}_{\mathrm{A} 0}$.

\section{Statistical Analysis}

All values are expressed as mean \pm SEM and were analyzed using a one-way ANOVA followed by a Newman-Keuls post hoc comparison test (Prism 4, GraphPad Software, San Diego, Calif., USA). Differences were considered statistically significant at $\mathrm{p}<0.05$.

\section{Results}

\section{Effects of Amlodipine on Metabolic Factors}

As expected, diabetic animals had $\mathrm{HbAl}_{\mathrm{C}}$ levels $>9 \%$ (table 1); these values were similar in all treatment groups. Diabetic animals also exhibited an average of $28 \%$ decrease in body weight, $74 \%$ increase in kidney/body weight, as well as $23 \%$ increase in heart/body weight ratio as compared with the nondiabetic animals (table 1). Treatment with amlodipine had no further effect on these parameters. Both food $(\sim 78 \%)$ and water $(\sim 398 \%)$ intake were increased in the diabetic compared with the nondiabetic rats (table 1). While treatment with amlodipine did not affect food intake in the diabetic animals, the highest dose of amlodipine $\left(20 \mathrm{mg} / \mathrm{kg}, \mathrm{D}_{\mathrm{A} 20}\right)$ further increased water intake by $30 \%$. Accordingly, urine output was increased in all diabetic animals, including the ones treated with $20 \mathrm{mg} / \mathrm{kg}$ of amlodipine.

\section{Effects of Amlodipine on Blood Pressure and Renal Function}

Blood pressure levels were similar in nondiabetic, $\mathrm{D}_{\mathrm{A} 0}, \mathrm{D}_{\mathrm{A} 5}$ and $\mathrm{D}_{\mathrm{A} 10}$ animals (table 1). However, in $\mathrm{D}_{\mathrm{A} 20}$ animals, there was a $20 \%$ increase in MAP compared with both the nondiabetic and diabetic group (table 1).

No differences in urine albumin excretion (UAE) were observed after 4 and 8 weeks of treatment between any of the treatment groups (fig. 1a). However, after 12 weeks of hyperglycemia, diabetic animals exhibited a $228 \%$ increase in UAE compared with the nondiabetics (fig. 1a). This diabetes-associated increase in UAE was exaggerated with amlodipine treatment, especially at the highest dose $(20 \mathrm{mg} / \mathrm{kg}$, fig. 1a).

As widely reported, the STZ-induced diabetic rat is in a state of glomerular hyperfiltration even after 12 weeks of hyperglycemia. Specifically, diabetic rats had a $32 \%$ increase in 

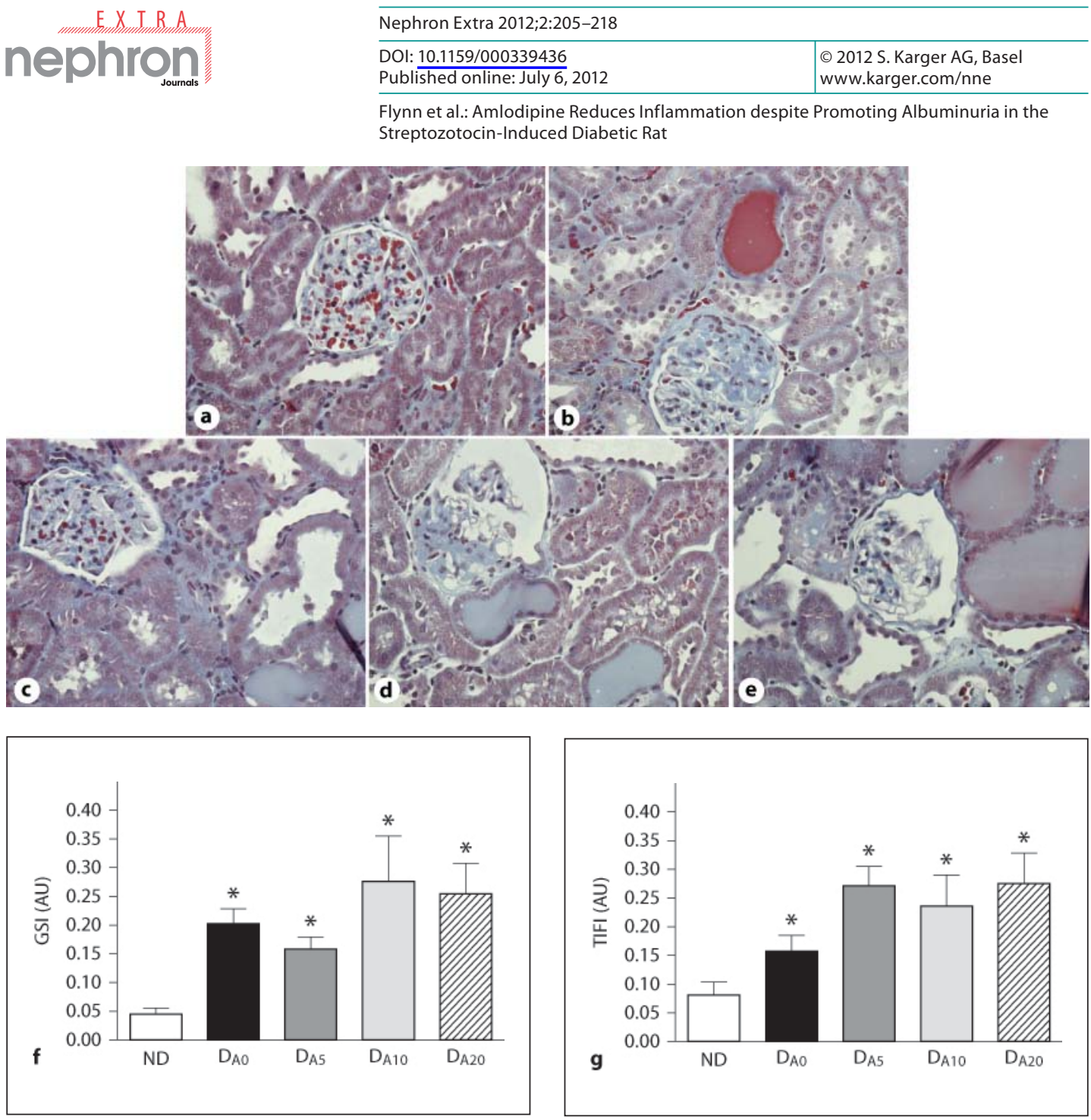

Fig. 2. Effects of amlodipine on renal pathology in the STZ-induced diabetic rat. a-e Masson's trichromestained sections. a Nondiabetic $(\mathrm{ND})$, b diabetic $\left(\mathrm{D}_{\mathrm{A} 0}\right)$, c diabetic treated with $5 \mathrm{mg} / \mathrm{kg}$ amlodipine $\left(\mathrm{D}_{\mathrm{A} 5}\right)$, d diabetic treated with $10 \mathrm{mg} / \mathrm{kg}$ amlodipine $\left(\mathrm{D}_{\mathrm{A10}}\right)$, e diabetic treated with $20 \mathrm{mg} / \mathrm{kg}$ amlodipine $\left(\mathrm{D}_{\mathrm{A} 20}\right)$. f Index of glomerulosclerosis (GSI) expressed in arbitrary units (AU). g Index of tubulointerstitial fibrosis (TIFI) expressed in arbitrary units (AU). Values are means \pm SE. ND, $n=8 ; D_{A 0}, n=10 ; D_{A 5}, n=10 ; D_{A 10}$, $\mathrm{n}=8 ; \mathrm{D}_{\mathrm{A} 20}, \mathrm{n}=7 .^{*} \mathrm{p}<0.05$ versus ND.

GFR compared with the nondiabetics (fig. 1b). All three doses of amlodipine abolished this diabetes-associated glomerular hyperfiltration (fig. 1b).

\section{Effects of Amlodipine on Renal Pathology}

The STZ-induced diabetic rat was characterized by moderate mesangial expansion contributing to glomerulosclerosis and presence of tubular casts, accumulation of extracellular matrix proteins and inflammatory cells in the interstitium, contributing to tubulointerstitial fibrosis (fig. 2b). Treatment with amlodipine, regardless of the dose, had no further effect on diabetes-associated renal injury (fig. 2c). This observation was further supported by semiquantitative analysis of the indices of glomerulosclerosis (GSI) and tubulointerstitial fibrosis (TIFI). In the diabetics, both GSI and TIFI were increased on average by $25 \%$ and $78 \%$, respectively, as compared with untreated diabetic rats (fig. $2 \mathrm{f}, \mathrm{g}$ ). Treatment with amlodipine resulted in GSI and TIFI similar to untreated diabetic rats. 


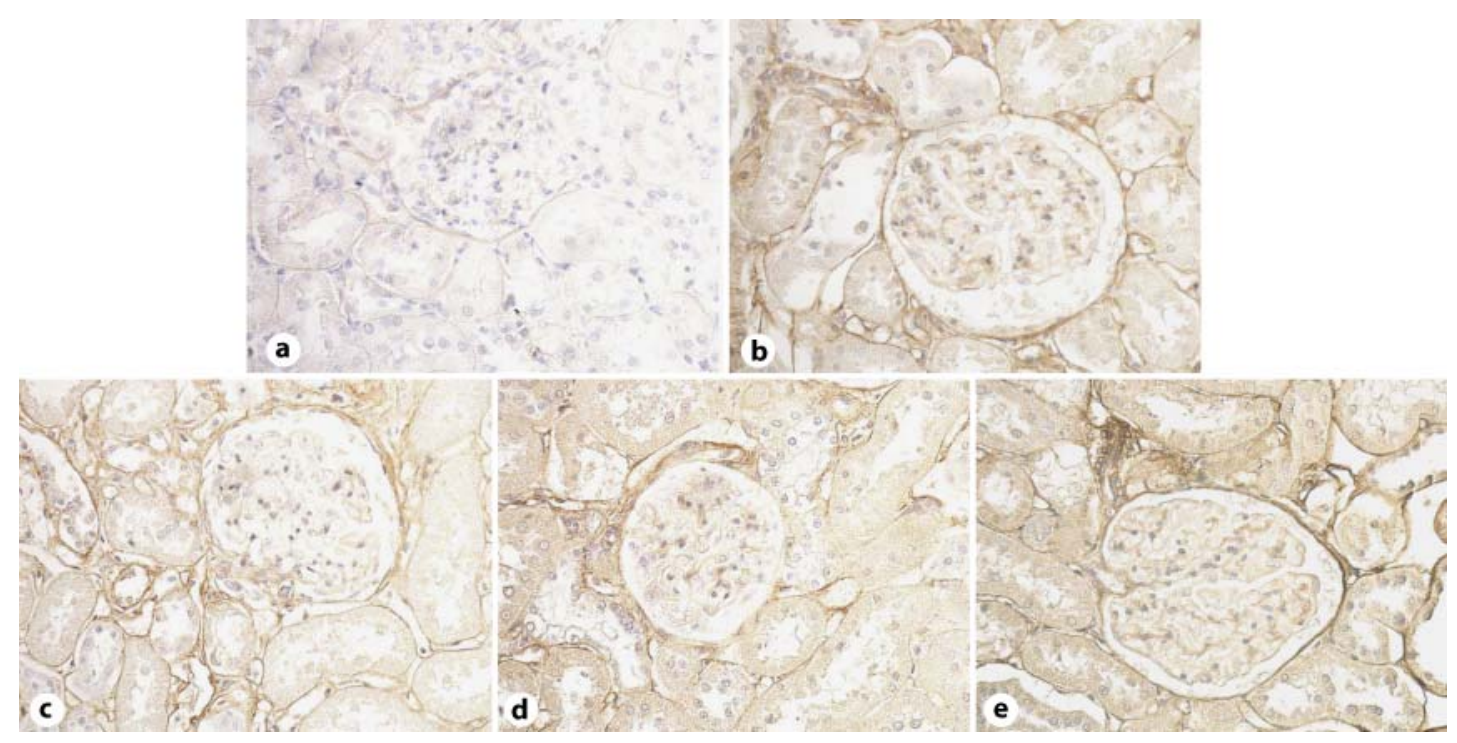

Fig. 3. Effects of amlodipine on collagen type IV protein expression and immunolocalization in the STZ-induced diabetic rat. a-e Immunohistochemical staining for collagen type IV. a Nondiabetic $(\mathrm{ND})$, b diabetic $\left(\mathrm{D}_{\mathrm{A} 0}\right)$, c diabetic treated with $5 \mathrm{mg} / \mathrm{kg}$ amlodipine $\left(D_{\mathrm{A} 5}\right)$, d diabetic treated with $10 \mathrm{mg} / \mathrm{kg}$ amlodipine $\left(\mathrm{D}_{\mathrm{A} 10}\right)$, e diabetic treated with $20 \mathrm{mg} / \mathrm{kg}$ amlodipine $\left(\mathrm{D}_{\mathrm{A} 20}\right)$. Original magnification $\times 400$. $f$ Collagen type IV protein expression. Top panel, representative immunoblot of collagen type IV (Coll IV) protein expression. Bottom panel, densitometric scans in relative optical density (ROD) expressed as a ratio of Coll IV/ $\beta$-actin. Values are means \pm SE. ND, $\mathrm{n}=8 ; \mathrm{D}_{\mathrm{A} 0}, \mathrm{n}=10 ; \mathrm{D}_{\mathrm{A} 5}$, $\mathrm{n}=10 ; \mathrm{D}_{\mathrm{A} 10}, \mathrm{n}=8 ; \mathrm{D}_{\mathrm{A} 20}, \mathrm{n}=7 .{ }^{*} \mathrm{p}<0.05$ versus ND.

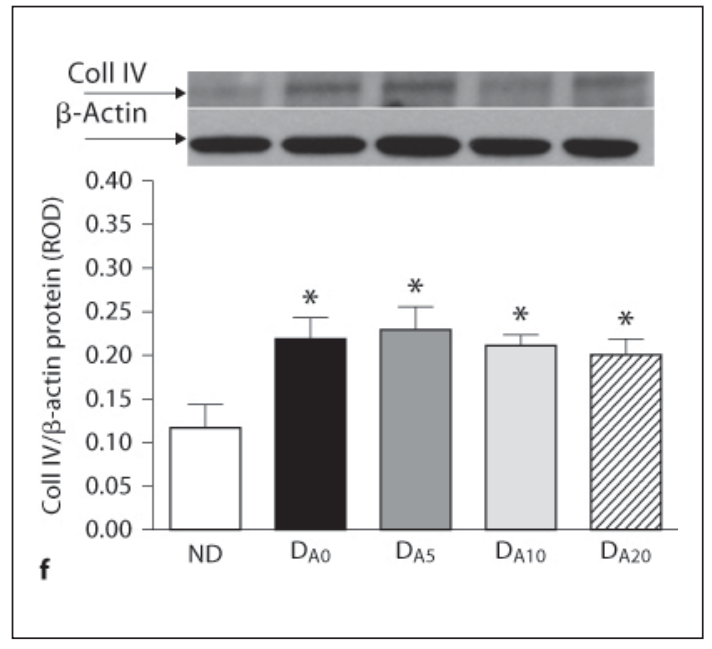

In the renal cortex of diabetic rats, collagen type IV was immunolocalized to basement membranes of proximal and distal tubules and expanded mesangial areas in the glomerulus (fig. 3b). Treatment with all three doses of amlodipine had no further effect on the pattern of type IV collagen immunolocalization (fig. 3c-e). Quantitative analysis of collagen type IV protein expression by Western blotting confirmed the immunohistochemical observations. In renal cortical samples of untreated diabetic rats, collagen type IV protein expression was increased by $86 \%$ as compared with the nondiabetic rats (fig. $3 \mathrm{f}$ ). Collagen type IV expression remained elevated after treatment with amlodipine regardless of the dose (fig. 3f).

\section{Effect of Amlodipine on Inflammatory Markers}

In the renal cortex of diabetic rats, TGF- $\beta$ was predominantly immunolocalized around podocytes and proximal tubules (fig. $4 \mathrm{~b}$ ). The apparent intensity of immunostaining was decreased in the animals treated with all three doses of amlodipine (fig. $4 \mathrm{~d}$, e). Western blot analysis ( $50-\mathrm{kDa}$ band) showed a $178 \%$ increase in TGF- $\beta$ protein expression in untreated diabetic compared with nondiabetic rats (fig. $4 \mathrm{f})$. While 5 and $10 \mathrm{mg} / \mathrm{kg}$ of amlodipine $\left(\mathrm{D}_{\mathrm{A} 5}\right.$ 


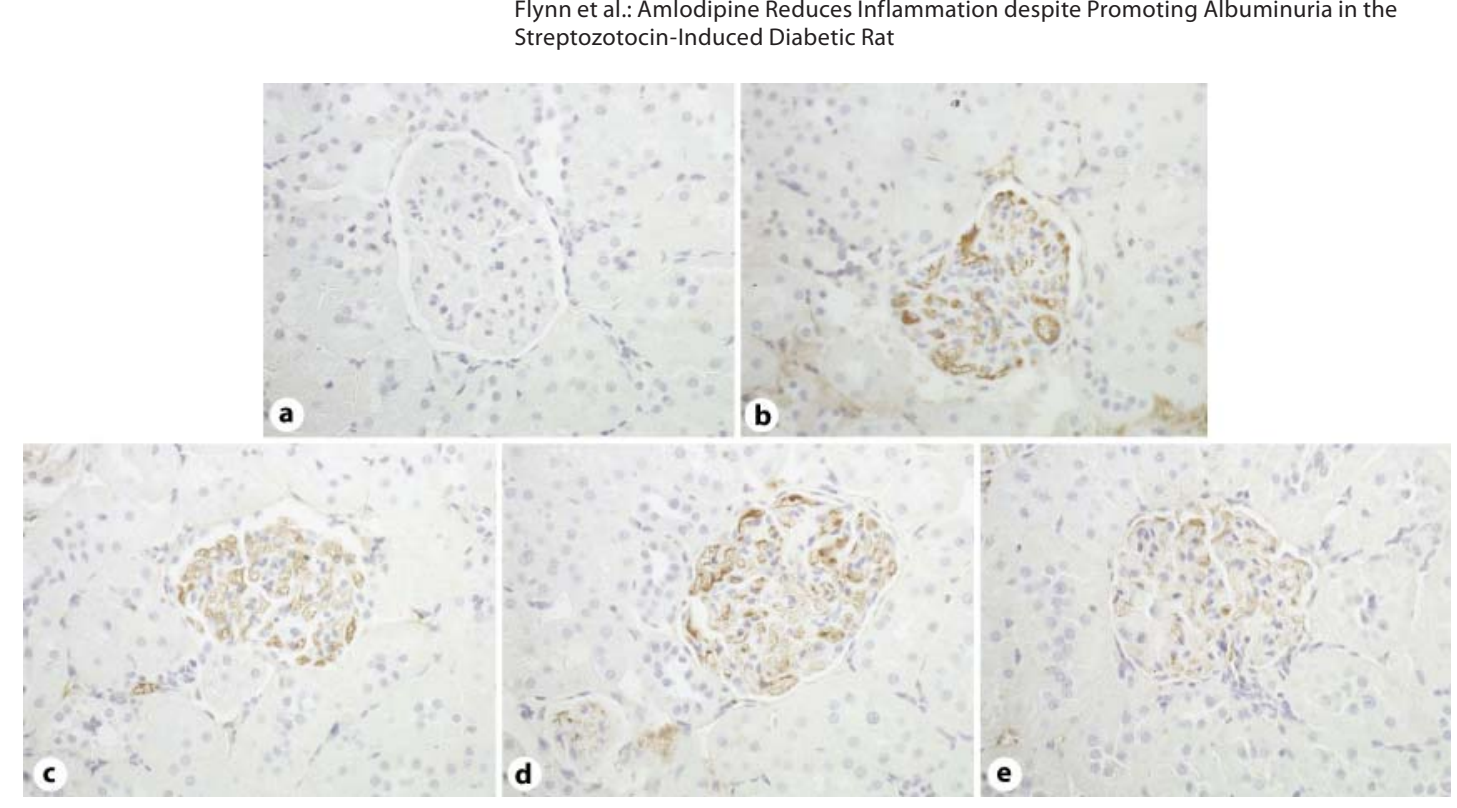

Fig. 4. Effects of amlodipine on TGF- $\beta$ protein expression and immunolocalization in the STZ-induced diabetic rat. a-e Immunohistochemical staining for TGF- $\beta$. a Nondiabetic (ND), b diabetic $\left(D_{A 0}\right)$, c diabetic treated with $5 \mathrm{mg} / \mathrm{kg}$ amlodipine $\left(D_{\mathrm{A} 5}\right)$, d diabetic treated with $10 \mathrm{mg} / \mathrm{kg}$ amlodipine $\left(D_{\mathrm{A} 10}\right)$, e diabetic treated with $20 \mathrm{mg} / \mathrm{kg}$ amlodipine $\left(D_{A 20}\right)$. Original magnification $\times 400$. f TGF- $\beta$ protein expression. Top panel, representative immunoblot of TGF- $\beta$ protein expression. Bottom panel, densitometric scans in relative optical density (ROD) expressed as a ratio of TGF- $\beta / \beta$ actin. Values are means \pm SE. ND, $\mathrm{n}=8 ; \mathrm{D}_{\mathrm{A} 0}, \mathrm{n}=$ $10 ; \mathrm{D}_{\mathrm{A} 5}, \mathrm{n}=10 ; \mathrm{D}_{\mathrm{A} 10}, \mathrm{n}=8 ; \mathrm{D}_{\mathrm{A} 20}, \mathrm{n}=7 .{ }^{*} \mathrm{p}<0.05$ versus $\mathrm{ND} ;{ }^{*} \mathrm{p}<0.05$ versus $\mathrm{D}_{\mathrm{A} 0}$.

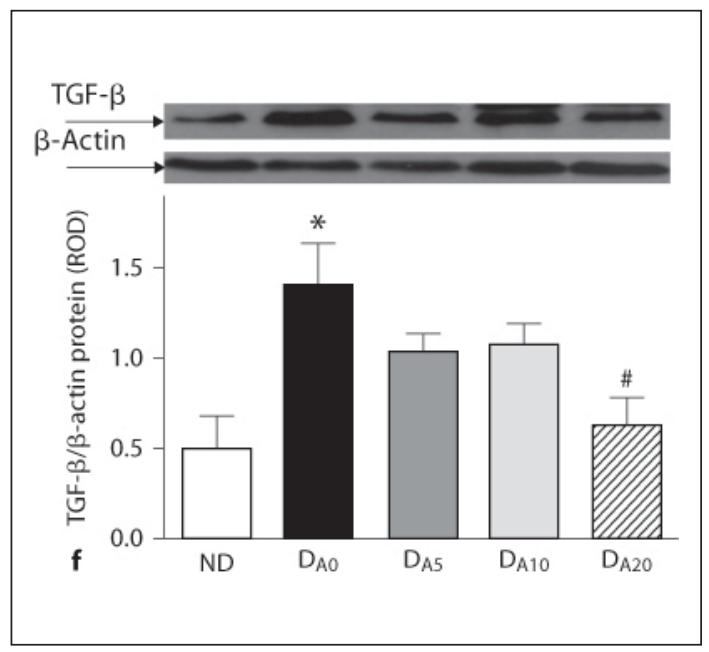

and $\mathrm{D}_{\mathrm{A} 10}$, respectively) tended to attenuate diabetes-associated increase in TGF- $\beta$ protein expression, only $\mathrm{D}_{\mathrm{A} 20}$ reduced TGF- $\beta$ protein expression to levels similar to that of untreated diabetic rats (fig. 4f).

CD68-positive cells, indicating the presence of macrophages, were prominent in glomeruli and tubulointerstitial areas in the kidneys of diabetic rats (fig. 5b). In the untreated diabetic rats, there was a $167 \%$ and $92 \%$ increase in the abundance of CD68-positive cells in the glomeruli and cortical tubulointerstitium, respectively, as compared with nondiabetic rats (fig. 5a, b). All three doses of amlodipine equally reduced abundance of CD68-positive cells to levels similar to that of nondiabetic rats (fig. $5 \mathrm{c}-\mathrm{e}$ ).

\section{Discussion}

The present study examined the effects of a dihydropyridine CCB, amlodipine, on renal functional and structural changes in the STZ-induced diabetic rat over 12 weeks. The study shows beneficial effects of amlodipine on diabetes-associated renal inflammation and pos- 
Streptozotocin-Induced Diabetic Rat
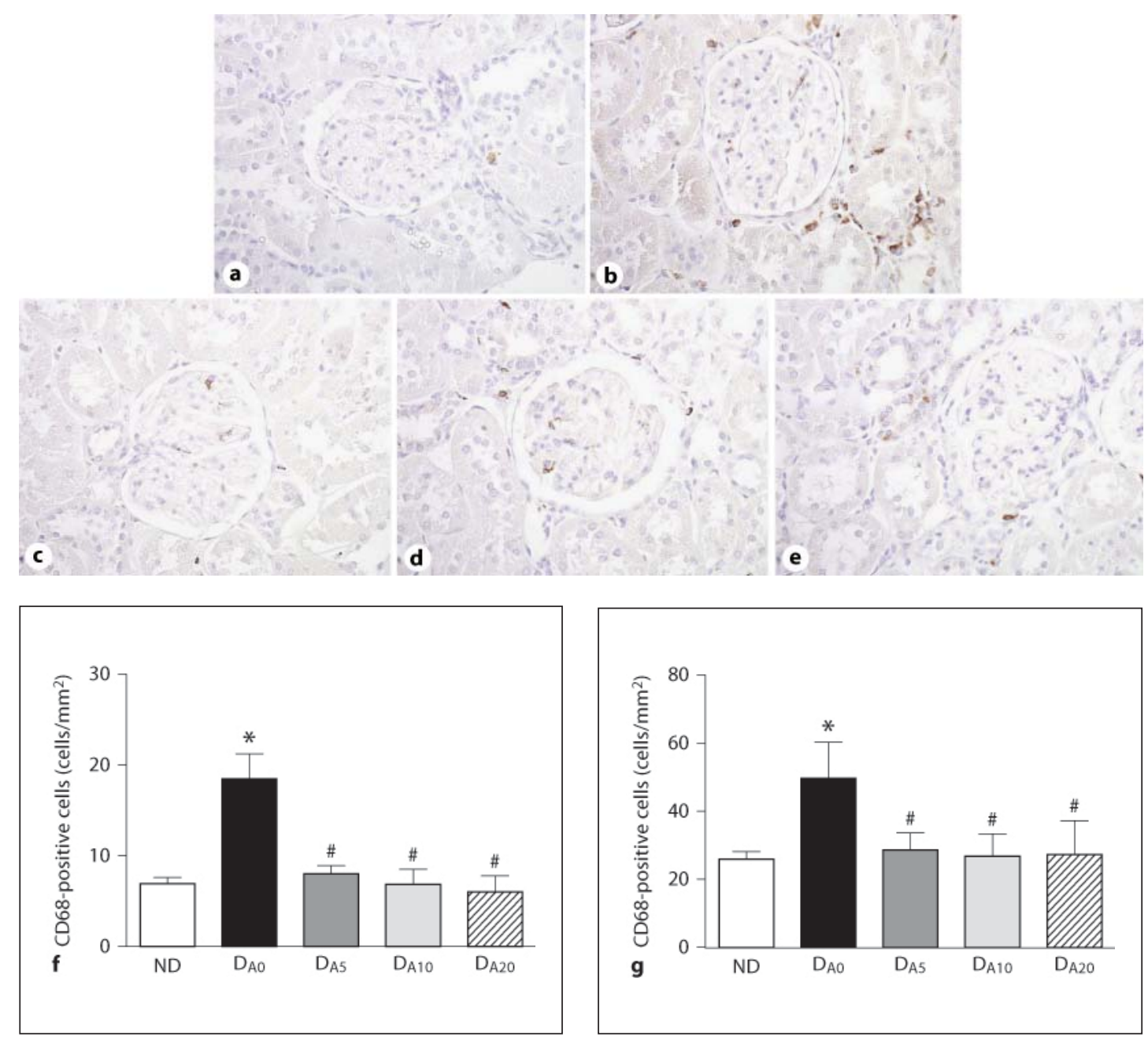

Fig. 5. Effects of amlodipine on macrophage infiltration in the STZ-induced diabetic rat. a-e Immunohistochemical staining for CD68. a Nondiabetic $(\mathrm{ND})$, b diabetic $\left(\mathrm{D}_{\mathrm{A} 0}\right), \mathbf{c}$ diabetic treated with $5 \mathrm{mg} / \mathrm{kg}$ amlodipine $\left(D_{A 5}\right)$, d diabetic treated with $10 \mathrm{mg} / \mathrm{kg}$ amlodipine $\left(D_{A 10}\right)$, e diabetic treated with $20 \mathrm{mg} / \mathrm{kg}$ amlodipine $\left(\mathrm{D}_{\mathrm{A} 20}\right)$. Original magnification $\times 400$. $\mathbf{f}$ Quantitative analysis of CD68 staining in the glomeruli expressed as CD68-positive cells $/ \mathrm{mm}^{2}$. $\mathbf{g}$ Quantitative analysis of CD68 staining in the cortical tubulointerstitium expressed as CD68-positive cells $/ \mathrm{mm}^{2}$. Values are means \pm SE. ND, $\mathrm{n}=8 ; \mathrm{D}_{\mathrm{A} 0}, \mathrm{n}=$ 10; $\mathrm{D}_{\mathrm{A} 5}, \mathrm{n}=10 ; \mathrm{D}_{\mathrm{A} 10}, \mathrm{n}=8 ; \mathrm{D}_{\mathrm{A} 20}, \mathrm{n}=7 .{ }^{*} \mathrm{p}<0.05$ versus $\mathrm{ND} ;{ }^{*} \mathrm{p}<0.05$ versus $\mathrm{D}_{\mathrm{A} 0}$.

sibly glomerular hyperfiltration; however, it has adverse effects on albuminuria, blood pressure and renal structural damage, especially at high doses. These data suggest differential effects of amlodipine in the STZ-induced diabetic rat, a nonhypertensive model of diabetic kidney injury.

While CCBs, either alone or in combination with blockers of the RAS, are widely used in the treatment of hypertension [3-8], the evidence for their additional renoprotective effect in either nondiabetic or diabetic renal disease remains controversial. In experimental models of hypertensive renal injury, such as the spontaneously hypertensive rat, the Dahl saltsensitive rat and in Sprague-Dawley rats after 5/6 renal ablation, CCBs lower blood pressure [23-26]. However, the effects of CCBs on blood pressure in the setting of diabetes are inconclusive. As previously reported, STZ-induced diabetes in Sprague-Dawley rats either exhibits 
no changes or slight reductions in systemic blood pressure as compared with the nondiabetic rat [27]. This is thought to be due to stimulation of the RAS as a counterbalancing antinatriuretic effect against the glucose-induced osmotic natriuresis and diuresis [27]. In the present study, no differences in MAP were observed in the STZ-induced compared with the nondiabetic rat. While lower doses of amlodipine had no effect on MAP either, the higher doses of amlodipine increased MAP. Our data suggest that the increase in blood pressure following treatment with amlodipine may be mediated through increases in renal renin activity. A similar increase in renin mRNA was also observed in normotensive Sprague-Dawley rats [28]. Previous studies examining the effects of amlodipine in experimental models of diabetic renal disease have shown variable effects on blood pressure, with some reporting no effect [29] and others showing an antihypertensive effect [30]. However, both of these studies used very low doses of amlodipine. Thus, it is likely that the effects of amlodipine on MAP are dose-dependent. One of the limitations of the present study is that MAP was only measured at the end of the treatment period in conscious animals with indwelling catheters. Thus, we acknowledge that MAP variability during the treatment period was possible and future studies, using telemetric monitoring should be performed to address this issue.

Several investigators have suggested that CCBs may exert renoprotective effects independent of and beyond their blood pressure-lowering effects. Even though a few clinical and experimental studies show that amlodipine does reduce albuminuria in diabetes [8], the present study shows that amlodipine increases UAE in the STZ-induced diabetic rat. Another study using the same experimental model showed no effects of a low dose $(3 \mathrm{mg} / \mathrm{kg})$ of amlodipine on UAE after a 4-month treatment [30]. The Irbesartan Diabetic Nephropathy Trial showed that amlodipine increased proteinuria within the first 30 months of treatment of patients with type 2 diabetes mellitus [6]. Furthermore, benidipine, the T-type CCB has been suggested to be more effective than amlodipine in protecting renal function in patients with diabetic nephropathy $[31,32]$ as well as in hypertensive patients with mild chronic kidney disease [33]. Furthermore, in experimental models of chronic renal injury, nifedipine increased albuminuria $[14,26]$. Thus, it appears that the effects of CCBs on albuminuria may be dependent on the dose as well as formulation of CCBs.

Consistent with previous studies, our study shows that the STZ-induced diabetic rat exhibits glomerular hyperfiltration [34]. The increase in GFR and intraglomerular pressure in early diabetes is thought to be mainly a consequence of afferent arteriolar vasodilation. Our study found that treatment with amlodipine abolished glomerular hyperfiltration, which can be interpreted in two ways. Since glomerular hyperfiltration is thought to be one of the initiators of glomerular injury, then reductions in GFR following treatment with amlodipine, as observed in the present study, could be considered renoprotective. However, it is more likely that amlodipine raised GFR early in the disease and returned to normal levels after 12 weeks due to glomerular injury. Variable effects of CCBs on GFR have been reported in other models and humans $[14,17,35]$. In patients with chronic, nondiabetic renal disease and in patients with mild to moderate essential hypertension, amlodipine increased GFR and glomerular capillary pressure [35]. In type 2 diabetic patients with hypertension and nephropathy a significant decrease in estimated GFR was observed after treatment with amlodipine [17]. Similarly, nifedipine has been shown to reduce GFR in the 5/6 renal ablation model [14]. These variable effects of CCBs on GFR are again likely to be due to differences in dose and formulation of CCBs as well as being dependent on the experimental model and disease.

Diabetic renal injury is characterized by glomerulosclerosis and tubulointerstitial fibrosis [36]. Our study shows that amlodipine has no further effect on either glomerular or tubulointerstitial injury or collagen type IV protein expression. Similarly, in Dahl salt-sensitive hypertensive rats fed either a 4 or $8 \% \mathrm{NaCl}$ diet [24] or the uninephrectomized Munich Wis- 
tar rat $[37,38]$, amlodipine had no effect on glomerulosclerosis or podocyte injury. Furthermore, in a novel mouse model of diabetic nephropathy, the megsin/receptor for advanced glycation end products/inducible nitric oxide synthase triple transgenic mouse, amlodipine had no effect on histological changes [39]. Thus, it appears that amlodipine may not play an important role on renal structural changes.

There is a growing body of evidence suggesting that diabetic nephropathy is associated with low-grade inflammation [40]. Our study confirms the previous reports of increased TGF- $\beta$ protein and the presence of activated macrophages in the diabetic kidney $[20,25]$. Interestingly, despite the fact that amlodipine appeared to exert adverse effects on the diabetic kidney, it reduced both TGF- $\beta$ protein and abundance of CD68-postive cells, suggesting it has anti-inflammatory properties. However, the fact that this was not sufficient to prevent renal injury suggests that additional mechanisms are responsible for mediating renal damage. Few studies to date have examined the effects of amlodipine on inflammation associated with either diabetic or nondiabetic renal disease. In Dahl salt-sensitive rats fed a high-sucrose diet, which mimics metabolic syndrome, amlodipine had no effect on ED-1positive cell infiltration [41]. However, in hypertensive patients with mild chronic kidney disease, blood interleukin-6 levels decreased after a 12-month treatment with amlodipine [33]. In advanced glycation end-products-exposed human cultured mesangial cells nifedipine, another dihydropyridine-based CCB, reduces expression of monocyte chemoattractant protein-1, a principal chemokine that mediates the recruitment of monocytes to inflammatory sites [42]. These findings suggest that CCBs may indeed play a protective role against diabetic nephropathy partly through its anti-inflammatory properties. However, additional studies are needed to examine the specific mechanisms by which CCBs reduce inflammation and how this contributes to the pathogenesis of the disease.

The present study provides evidence for both beneficial and adverse effects of amlodipine in the STZ-induced diabetic kidney. While it reduces markers of inflammation, it exacerbates renal hemodynamic without affecting renal structural changes. Many of these effects may be dependent on the animal strain, dose of the drug and also underlying physiological function. Thus, further studies are warranted in order to evaluate the effects of high-dose amlodipine monotherapy in normotensive diabetic kidney disease.

\section{Acknowledgements}

The authors would like to thank Ms. Stephanie Evans for technical assistance with paraffin sectioning and Ms. Haiyan Zhang for measurement of renin activity. This work was supported by an Investigator-initiated collaborative grant from Boehringer-Ingelheim to C. Maric-Bilkan and PO1 grant (HL51971) to J.E. Hall for the support of core facilities used for part of the study.

\section{Disclosure Statement}

The authors have no conflicts of interest to disclose. 


\section{References}

-1 Epstein BJ, Vogel K, Palmer BF: Dihydropyridine calcium channel antagonists in the management of hypertension. Drugs 2007;67:1309-1327.

-2 Shimosawa T, Gohchi K, Yatomi Y, Fujita T: Effectiveness of add-on low-dose diuretics in combination therapy for hypertension: losartan/hydrochlorothiazide vs. candesartan/amlodipine. Hypertens Res 2007;30:831-837.

-3 Fogari R, Derosa G, Zoppi A, Preti P, Lazzari P, Destro M, Fogari E, Rinaldi A, Mugellini A: Effect of telmisartan-amlodipine combination at different doses on urinary albumin excretion in hypertensive diabetic patients with microalbuminuria. Am J Hypertens 2007;20:417-422.

-4 Yasuda G, Ando D, Hirawa N, Umemura S, Tochikubo O: Effects of losartan and amlodipine on urinary albumin excretion and ambulatory blood pressure in hypertensive type 2 diabetic patients with overt nephropathy. Diabetes Care 2005;28:1862-1868.

-5 Yilmaz MI, Carrero JJ, Martin-Ventura JL, Sonmez A, Saglam M, Celik T, Yaman H, Yenicesu M, Eyileten T, Moreno JA, Egido J, Blanco-Colio LM: Combined therapy with renin-angiotensin system and calcium channel blockers in type 2 diabetic hypertensive patients with proteinuria: effects on soluble TWEAK, PTX3, and flow-mediated dilation. Clin J Am Soc Nephrol 2010;5:1174-1181.

-6 Atkins RC, Briganti EM, Lewis JB, Hunsicker LG, Braden G, Champion de Crespigny PJ, DeFerrari G, Drury P, Locatelli F, Wiegmann TB, Lewis EJ: Proteinuria reduction and progression to renal failure in patients with type 2 diabetes mellitus and overt nephropathy. Am J Kidney Dis 2005;45:281287.

-7 Bakris GL, Sarafidis PA, Weir MR, Dahlof B, Pitt B, Jamerson K, Velazquez EJ, Stakos-Byrne L, Kelly RY, Shi V, Chilang YT, Weber MA: Renal outcomes with different fixed-dose combination therapies in patients with hypertension at high risk for cardiovascular events (ACCOMPLISH): a prespecified secondary analysis of a randomised controlled trial. Lancet 2010;375:1173-1181.

-8 Krimholtz MJ, Karalliedde J, Thomas S, Bilous R, Viberti G: Targeting albumin excretion rate in the treatment of the hypertensive diabetic patient with renal disease. J Am Soc Nephrol 2005;16(suppl 1):S42-S47.

-9 Miyagawa K, Dohi Y, Nakazawa A, Sugiura T, Yamashita S, Sato K, Kimura G: Renoprotective effect of calcium channel blockers in combination with an angiotensin receptor blocker in elderly patients with hypertension. A randomized crossover trial between benidipine and amlodipine. Clin Exp Hypertens 2010;32:1-7.

-10 Iino Y, Hayashi M, Kawamura T, Shiigai T, Tomino Y, Yamada K, Kitajama T, Ideura T, Koyama A, Sugisaki T, Suzuki H, Umemura S, Kawaguchii Y, Uchida S, Kuwahara M, Yamazaki T: Renoprotective effect of losartan in comparison to amlodipine in patients with chronic kidney disease and hypertension - a report of the Japanese Losartan Therapy Intended for the Global Renal Protection in Hypertensive Patients (JLIGHT) study. Hypertens Res 2004;27:21-30.

-11 Griffin KA, Bidani AK: Potential risks of calcium channel blockers in chronic kidney disease. Curr Cardiol Rep 2008; 10:448-455.

-12 Herlitz H, Harris K, Risler T, Boner G, Bernheim J, Chanard J, Aurell M: The effects of an ACE inhibitor and a calcium antagonist on the progression of renal disease: the Nephros Study. Nephrol Dial Transplant 2001;16:2158-2165.

-13 Griffin KA, Picken MM, Bakris GL, Bidani AK: Class differences in the effects of calcium channel blockers in the rat remnant kidney model. Kidney Int 1999;55:1849-1860.

-14 Griffin KA, Picken MM, Bidani AK: Deleterious effects of calcium channel blockade on pressure transmission and glomerular injury in rat remnant kidneys. J Clin Invest 1995;96:793-800.

-15 Foley RN, Collins AJ: End-stage renal disease in the United States: an update from the United States Renal Data System. J Am Soc Nephrol 2007;18:2644-2648.

-16 Parving HH, Tarnow L, Rossing P: Renal protection in diabetes: an emerging role for calcium antagonists. J Hypertens Suppl 1996;14:S21-S25.

-17 Sasaki H, Saiki A, Endo K, Ban N, Yamaguchi T, Kawana H, Nagayama D, Ohhira M, Oyama T, Miyashita Y, Shirai K: Protective effects of efonidipine, a T- and L-type calcium channel blocker, on renal function and arterial stiffness in type 2 diabetic patients with hypertension and nephropathy. J Atheroscler Thromb 2009; 16:568-575.

- 18 Brown SA, Walton CL, Crawford P, Bakris GL: Long-term effects of antihypertensive regimens on renal hemodynamics and proteinuria. Kidney Int 1993;43:1210-1218. 
Flynn et al.: Amlodipine Reduces Inflammation despite Promoting Albuminuria in the

Streptozotocin-Induced Diabetic Rat

19 Gaber L, Walton C, Brown S, Bakris G: Effects of different antihypertensive treatments on morphologic progression of diabetic nephropathy in uninephrectomized dogs. Kidney Int 1994;46:161-169.

20 Mankhey R, Wells CC, Bhatti F, Maric C: 17-beta estradiol supplementation reduces tubulointerstitial fibrosis by increasing MMP activity in the diabetic kidney. Am J Physiol Regul Integr Comp Physiol 2007;292:R769-R777.

-21 Kantorowicz L, Valego NK, Tang L, Figueroa JP, Chappell MC, Carey LC, Rose JC: Plasma and renal renin concentrations in adult sheep after prenatal betamethasone exposure. Reprod Sci 2008;15: 831-838.

-22 Haber E, Koerner T, Page LB, Kliman B, Purnode A: Application of a radioimmunoassay for angiotensin I to the physiologic measurements of plasma renin activity in normal human subjects. J Clin Endocrinol Metab 1969;29:1349-1355.

-23 Lehfeld LS, Silveira LA, Ghini B, Lopes de Faria JB: Early blood pressure normalization independent of the class of antihypertensive agent prevents augmented renal fibronectin and albuminuria in experimental diabetic nephropathy. Kidney Blood Press Res 2004;27:114-120.

-24 Du J, Fan YY, Hitomi H, Kiyomoto H, Kimura S, Kong CZ, Noma T, Kohno M, Nishiyama A, Nakano D: Mineralocorticoid receptor blockade and calcium channel blockade have different renoprotective effects on glomerular and interstitial injury in rats. Am J Physiol Renal Physiol 2009; 297:F802-F808.

25 Xu Q, Wells CC, Garman JH, Asico L, Escano CS, Maric C: Imbalance in sex hormone levels exacerbates diabetic renal disease. Hypertension 2008;51:1218-1224.

-26 Griffin KA, Picken M, Bakris GL, Bidani AK: Comparative effects of selective T- and L-type calcium channel blockers in the remnant kidney model. Hypertension 2001;37:1268-1272.

-27 Brands MW, Labazi H: Role of glomerular filtration rate in controlling blood pressure early in diabetes. Hypertension 2008;52:188-194.

-28 Schricker K, Hamann M, Macher A, Kramer BK, Kaissling B, Kurtz A: Effect of amlodipine on renin secretion and renin gene expression in rats. Br J Pharmacol 1996;119:744-750.

-29 Ma G, Allen TJ, Cooper ME, Cao Z: Calcium channel blockers, either amlodipine or mibefradil, ameliorate renal injury in experimental diabetes. Kidney Int 2004;66:1090-1098.

-30 de Cavanagh EM, Ferder L, Toblli JE, Piotrkowski B, Stella I, Fraga CG, Inserra F: Renal mitochondrial impairment is attenuated by AT1 blockade in experimental Type I diabetes. Am J Physiol Heart Circ Physiol 2008;294:H456-H465.

- 31 Abe M, Okada K, Maruyama T, Maruyama N, Matsumoto K: Comparison of the antiproteinuric effects of the calcium channel blockers benidipine and amlodipine administered in combination with angiotensin receptor blockers to hypertensive patients with stage 3-5 chronic kidney disease. Hypertens Res 2009;32:270-275.

-32 Gashti CN, Bakris GL: The role of calcium antagonists in chronic kidney disease. Curr Opin Nephrol Hypertens 2004;13:155-161.

- 33 Nakamura T, Sato E, Fujiwara N, Kawagoe Y, Ueda Y, Sugaya T, Yamagishi S, Yamada S, Koide H: Comparative effects of benidipine and amlodipine on proteinuria, urinary 8-OHdG, urinary LFABP, and inflammatory and atherosclerosis markers in early-stage chronic kidney disease. Am J Med Sci 2010;339:157-163.

-34 Vallon V, Wead LM, Blantz RC: Renal hemodynamics and plasma and kidney angiotensin II in established diabetes mellitus in rats: effect of sodium and salt restriction. J Am Soc Nephrol 1995;5: 1761-1767.

- 35 Morrone LF, Ramunni A, Fassianos E, Saracino A, Coratelli P, Passavanti G: Nitrendipine and amlodipine mimic the acute effects of enalapril on renal haemodynamics and reduce glomerular hyperfiltration in patients with chronic kidney disease. J Hum Hypertens 2003;17:487-493.

-36 Taft JL, Nolan CJ, Yeung SP, Hewitson TD, Martin FI: Clinical and histological correlations of decline in renal function in diabetic patients with proteinuria. Diabetes 1994;43:1046-1051.

- 37 Dworkin LD, Tolbert E, Recht PA, Hersch JC, Feiner H, Levin RI: Effects of amlodipine on glomerular filtration, growth, and injury in experimental hypertension. Hypertension 1996;27:245250.

-38 Yao K, Sato H, Ina Y, Suzuki K, Ohno T, Shirakura S: Renoprotective effects of benidipine in combination with angiotensin II type 1 receptor blocker in hypertensive Dahl rats. Hypertens Res 2003;26: 635-641. 
Flynn et al.: Amlodipine Reduces Inflammation despite Promoting Albuminuria in the Streptozotocin-Induced Diabetic Rat

-39 Ohtomo S, Ito M, Izuhara Y, Van Ypersele De Strihou C, Miyata T: Reduction of albuminuria by angiotensin receptor blocker beyond blood pressure lowering: evaluation in megsin/receptor for advanced glycation end products/inducible nitric oxide synthase triple transgenic diabetic nephropathy mouse model. Nephrology (Carlton) 2008;13:517-521.

-40 Saraheimo M, Teppo AM, Forsblom C, Fagerudd J, Groop PH: Diabetic nephropathy is associated with low-grade inflammation in Type 1 diabetic patients. Diabetologia 2003;46:1402-1407.

-41 Konda T, Enomoto A, Matsushita J, Takahara A, Moriyama T: The N- and L-type calcium channel blocker cilnidipine suppresses renal injury in Dahl rats fed a high-sucrose diet, an experimental model of metabolic syndrome. Nephron Physiol 2005;101:p1-p13.

42 Matsui T, Takeuchi M, Yamagishi S: Nifedipine, a calcium channel blocker, inhibits inflammatory and fibrogenic gene expressions in advanced glycation end product (AGE)-exposed fibroblasts via

mineralocorticoid receptor antagonistic activity. Biochem Biophys Res Commun 2010;396:566-570. 